\title{
MATERNAL MANAGEMENT OF THEIR CHILDREN WITH EPILEPSY
}

${ }^{1}$ Ghada Gamal Mohamed Badawy, ${ }^{2}$ Magda Mohamed El-Sayed Youssef, And ${ }^{3}$ Ohoud Youssef El-Sheikh.

${ }^{1}$.3Pediatric Nursing Department, Faculty of Nursing, Mansoura University

${ }^{2}$ Pediatric Nursing Department, Faculty of Nursing, Alexandria University

E-mail of corresponding author:hh.ghada@yahoo.com

\begin{abstract}
:
Epilepsy is a chronic neurological disorder, characterized by recurrent unprovoked seizures. Epilepsy starts in childhood in $60 \%$ of cases and most of the clinically significant aspects of the disease occur during childhood. Parents, especially the mothers, play the most significant role in helping their epileptic children adapt to their condition. This study aimed to assess mothers' management of their epileptic children. The study was conducted at the Epileptic Clinic of Mansoura University Children Hospital. A convenient sample of 100 mothers of children with epilepsy who are diagnosed as epilepsy since at least 6 months and free from other chronic disorders comprised the study sample. Mothers' management of their epileptic children was collected through a structured interview schedule developed by the researcher. Results Half of mothers have total management scores in managing their epileptic children were either "good: or "satisfactory". There were statistical significant differences found between mothers' management scores and their characteristics in area related to education and their level of education, where the older the age and the higher education the better management scores the mothers have. Therefore, educational programs are essential for mothers of epileptic children about care of their children and their community resources. Also, establishing a support group for epileptic children and their mothers is mandatory to support mothers' management.
\end{abstract}

Keywords: Epilepsy, Children, Management, Maternal

\section{Introduction:}

Epilepsy is defined as an abnormal electrical disturbance in one or more areas of the brain, which characterized by recurrent epileptic seizures originating in the brain ${ }^{(1)}$. It is also defined as a disorder characterized by recurrent unprovoked seizures; the term epilepsy can be used interchangeably with the term seizure disorder (2). Epilepsy is currently recognized by many countries and concerned associations as a public health problem $^{(3)}$.

Most epileptic patients have their first epileptic seizure before the age of 20 years. In Egypt, the prevalence rate in Assiut Governorate in Upper Egypt was 12.9 per 1,000 (4). Farghaly, et. al (2012) (5) revealed that the prevalence of epilepsy among Egyptian children in Al-Quseir city was 9/1000 children, with highest peak among neonates and during early infancy (0-2years), with annual incidence rate $82.7 / 100,000$ children and the prevalence of epilepsy was higher among males $(10.5 / 1000)$ than female children (7.4/1000).

Parents of children with epilepsy, like parents of children with many other chronic conditions, are faced with a constant feeling of uncertainty about their children's condition. This uncertainty can lead to a profound negative impact on the children's physical and psychosocial adjustment to living with a chronic condition ${ }^{(6)}$. 
Ghada Gamal Mohamed Badawy et. al.

Mothers often assume the primary responsibility for the medical care of their children. They play the most significant role in helping their epileptic children adapt to their condition. In practical terms their function include seeking treatment, ensuring their children's compliance with treatment, providing care before, during and after the attack, facilitating the children's functioning in and outside the home, and regulating the impact of other people's attitudes on their children ${ }^{(7)}$.

Nurses play an important role in the provision of advice, support, advocacy and education of families affected by epilepsy. Educate children with epilepsy and their families about the disorder, the range of treatment options, and the array of community services that might be helpful to achieve optimal self-management ${ }^{(8)}$.

\section{Aim of the study:}

The study aims to assess maternal management of their children with epilepsy.

\section{Materials and Method:}

\section{Materials:}

\section{Design:}

Explorative descriptive research design was utilized to reach the aim of the study.

\section{Setting:}

The study was conducted at the Epileptic Clinic of Mansoura University Children Hospital.

\section{Subjects:}

A convenient sample of 100 mothers of epileptic children with the following criteria constituted the subjects:

- Both sexes.

- Diagnosed with epilepsy for at least 6 months.

- Free from other chronic diseases.

Tool:

\section{Mothers' Management of their Epileptic}

\section{Children Interview Schedule}

It was developed by the researcher after thorough review of literature to assess the mothers' management of their children with epilepsy. It included three parts:
Part I: Characteristics of mothers and their children:

A. Characteristics of mothers as mothers' age, level of education, marital status, occupation, family income, and residency and family medical history.

B. Characteristics of children, such as, age, sex, birth order, number of siblings, level of education, previous academic failure or success, last year achievement and absenteeism rate, children's hobbies. It also included the children's medical history as onset of epilepsy, duration, frequency of seizures, seizures triggers factors, and history of hospital admission.

Part II: Mothers' management of their epileptic children:

A. Mothers' management before the epileptic attack includes two parts:

1. Seizures precautions.

2. Management of drugs.

B.Mothers' management during the epileptic attack

C. Mothers' management after the epileptic attack.

\section{Scoring System:}

\section{Management Scores:}

Scores were used to evaluate mothers' management where each step of practice was given one mark and zero mark if not done.

Total Management scores of mothers about epilepsy was 60 marks, distributed as follows:

Mothers' management before epileptic seizures 36 marks included: Seizures precautions 19 marks, drug management 17 marks, mothers' management during epileptic seizures 11 marks, mothers' management after epileptic seizures 13 marks.

Total score of Mothers' Management was classified as follows:

- Good for score $65 \%$ and more

- Satisfactory for score 40- less than $65 \%$

- Unsatisfactory for score less than $40 \%$ 


\section{Results}

Characteristics of mothers are presented in Table (1). It is revealed from the table that slightly more than half of the studied mothers were in the age 30 to less than 40 years $(53.0 \%)$, while $32.0 \%$ were in the age 20 to less than 30 years with a mean age $33.29+6.47$ years. Slightly more than half of the mothers had completed secondary education $(52.0 \%)$, while $12.0 \%$ of mothers were illiterate. Eighty three percent of mothers were housewives. The majority of mothers were residing in rural area $(83.0 \%)$ and only $35 \%$ of mothers reported that their income is sufficient.

Table (2) illustrated characteristics of children with epilepsy. It is revealed from the table that more than half of the studied children were in the age 6 to less than 12 years $(55.0 \%)$ with a mean age $8.71+$ years. More than two third of the studied children were males (62.0\%). Almost half of the children were in primary schools $(51.0 \%)$ and $18.0 \%$ were in preparatory schools, and $15.0 \%$ didn't attend school. Forty four percent of the children had 2 siblings.

It was found from Table (3) that $80.0 \%$ of them had a previous hospitalization due to epileptic seizures. Forty six point three percent were hospitalized for one time compared to $26.3 \%$ who were hospitalized for three times. Ninety seven percent of the epileptic children were following up regularly. It was found that the place of follow-up was not near to their home for $88.0 \%$ of the studied children.

Table (4) represents mothers' safety precautions for their children's epileptic seizures and aura. It is revealed from the table that $63.0 \%$ of the mothers notified the school about their children illness. Less than half of them avoided leaving their children in a bath tub full of water alone $(42.0 \%)$. More than one third of the mothers reported that they prevented their children from getting in contact with sharp objects $(39.0 \%)$ and $36.0 \%$ didn't leave their children to ride bicycle alone. Also, only $15.0 \%$ of the mothers' mentioned that they keep a note to record the seizures. Mothers reported that none of their children carry a medical alarm $(0.0 \%)$.

Concerning mothers' management of aura symptoms, it was clear from the same table that less than two third of mothers stay with their children when they feel the aura symptoms $(60 \%)$. More than half of the mothers stated that they keep things that may cause injury away from their children $(56.0 \%)$. While, $26.0 \%$ of the mothers roll their children on their side on the ground.

Mothers' drug management is illustrated in Table (5). It was found that more than two third of the mothers gave the AEDs on times $(68.0 \%)$ and $51.0 \%$ didn't use the alternatives drugs without medical consultation.

Concerning mothers' management for prevention of dosing forgetfulness, $47.0 \%$ of the mothers mentioned that they link the drug with a daily routine and $23.0 \%$ set the alarm clock. Also, the management of side-effects of AEDs, more than half of the mothers didn't give attention to these sideeffects as they do not relate the sideeffects to AEDs (58.0\%) and 33.0\% ask the doctor.

Table (6) represents maternal management of their children during epileptic seizures. It is revealed from the table that all mothers stated that they stay with their children until seizure ends and restore their consciousness (100\%). Eighty four percent of the mothers mentioned that they remove hard objects that cause injury (84.0\%) and $61.0 \%$ loosen tight clothes around neck $\&$ chest. About one third of the mothers time the duration of the seizures $(36.0 \%)$.

It is clear from the same table that some of the harmful unnecessary procedures followed by mothers were bribe face with water which was reported by $62.0 \%$ of mothers and $39 \%$ restraining their children. 
Maternal management of their children after the epileptic seizures is illustrated in Table (7). It was found that almost all the mothers clean children's mouth from saliva $(99.0 \%)$ and $94.0 \%$ usually observe their children's level of awareness. Three quarters of the mothers stated that they observe child's breathing and general condition $(75.0 \%)$ and $72.0 \%$ examine the child for involuntary urination or defecation during the epileptic seizures.

Concerning the recording of epileptic seizures, it is revealed from the same table that the minority of the mothers record the time and duration of seizures $(12.0 \%$ and $13.0 \%$ respectively).

Figure (1) presents mothers' source of information regarding management of epilepsy. It is revealed from the figure that the majority of the mothers reported that their own experience was the source of their information $(87.0 \%)$. Twenty one percent of the mothers gained their information from the physician. Nurses were the source of information for only $11 \%$ of the mothers.

Mothers' management scores before, during, after and total management of their epileptic children were presented in Figure 2. It is revealed from the table that almost half of the mothers had "unsatisfactory" scores of their total management of their children epileptic seizures $(49.0 \%), 36.0 \%$ had "satisfactory" scores and $15.0 \%$ had "good" scores for their total management of their children epileptic seizures.
Regarding mothers' scores for their management before the epileptic seizures, $20.0 \%$ of the mothers had "good" and $24.0 \%$ had "satisfactory" scores of management before the epileptic seizures. Also, more than half of them had "unsatisfactory" scores of management before their children epileptic seizures $(56.0 \%)$.

In relation to mothers' score for their management during the epileptic seizures, $22.0 \%$ and $43.0 \%$ of mothers had "good" and "satisfactory" scores respectively and $35.0 \%$ of mothers had "unsatisfactory" scores. Only $10.0 \%$ of the mothers had "good" scores regarding management after the epileptic seizures and $35.0 \%$ had "satisfactory" scores and slightly more than half of them had "good" scores regarding their total management of their children epileptic seizures (55\%).

Table (8) presents mothers' total management scores of their epileptic children according to their characteristics. It is revealed from the table that mothers' management scores are not influenced by their age where no significant differences were found ( $\mathrm{P}=0.991)$. Also, it is clear that $60.0 \%$ and $75.0 \%$ of mothers who completed their secondary / diploma and university education had "good" and "satisfactory" scores respectively in their total management and the difference was statistically significant $(\mathrm{P}=0.000)$. It was also noticed that $85.7 \%$ of the mothers who had "unsatisfactory" scores in their management were from rural residence and the difference was statistically significant $(\mathrm{P}=0.003)$. 
MATERNAL MANAGEMENT OF THEIR etc...

\begin{tabular}{|c|c|c|}
\hline \multicolumn{3}{|c|}{ Table (1): Characteristics of Mother } \\
\hline \multirow[t]{2}{*}{ Characteristics } & \multicolumn{2}{|c|}{$\begin{array}{c}\text { Mothers } \\
(\mathbf{n}=100)\end{array}$} \\
\hline & No & $\%$ \\
\hline \multicolumn{3}{|l|}{ Age / years } \\
\hline - $<20$ & 2 & .02 \\
\hline - $20-$ & 32 & $32 \cdot$ \\
\hline $30-$ & 53 & 53.0 \\
\hline - $40 \&$ more & 13 & 13.0 \\
\hline Range & \multirow{2}{*}{\multicolumn{2}{|c|}{$\begin{array}{r}19.0-48.0 \\
33.29 \pm 6.47\end{array}$}} \\
\hline Mean \pm SD & & \\
\hline \multicolumn{3}{|l|}{ Education } \\
\hline - $\quad$ Illiterate & 12 & 12.0 \\
\hline - $\quad$ Read and write & 3 & 3.0 \\
\hline - $\quad$ Primary & 9 & 9.0 \\
\hline - $\quad$ Preparatory & 16 & 16.0 \\
\hline - $\quad$ Secondary & 52 & 52.0 \\
\hline $\begin{array}{ll}\text { - } & \text { Bachelor } \\
\text { Degree }\end{array}$ & 8 & 8.0 \\
\hline \multicolumn{3}{|l|}{ Work } \\
\hline - Working & 17 & 17.0 \\
\hline - $\quad$ Housewife & 83 & 83.0 \\
\hline \multicolumn{3}{|l|}{ Family income } \\
\hline - $\quad$ Sufficient & 35 & 35.0 \\
\hline - $\quad$ Insufficient & 65 & 65.0 \\
\hline \multicolumn{3}{|l|}{ Residence } \\
\hline - $\quad$ Rural & 83 & 83.0 \\
\hline - Urban & 17 & 17.0 \\
\hline
\end{tabular}

Table (2): Characteristics of Children With Epilepsy

\begin{tabular}{|c|c|c|}
\hline Characteristics & $\begin{array}{c}\text { No } \\
(n=100)\end{array}$ & $\%$ \\
\hline \multicolumn{3}{|l|}{ Child age / years } \\
\hline - $\quad<6$ & 28 & 28.0 \\
\hline - $6-$ & 55 & 55.0 \\
\hline - $\quad 12 \&$ more & 17 & 17.0 \\
\hline $\begin{array}{c}\text { Range } \\
\text { Mean } \pm \text { SD }\end{array}$ & \multicolumn{2}{|c|}{$\begin{array}{r}2.0-17.0 \\
8.71 \pm 3.38 \\
\end{array}$} \\
\hline \multicolumn{3}{|l|}{ Gender } \\
\hline - $\quad$ Male & 62 & 62.0 \\
\hline - $\quad$ Female & 38 & 38.0 \\
\hline \multicolumn{3}{|l|}{ Education } \\
\hline - $\quad$ Nursery & 13 & 13.0 \\
\hline - $\quad$ Primary & 51 & 51.0 \\
\hline - $\quad$ Preparatory & 18 & 18.0 \\
\hline - $\quad$ Secondary & 3 & 3.0 \\
\hline $\begin{array}{l}\text { - } \begin{array}{l}\text { Did not attend } \\
\text { school }\end{array} \\
\end{array}$ & 15 & 15.0 \\
\hline \multicolumn{3}{|l|}{$\begin{array}{l}\text { Number of } \\
\text { siblings }\end{array}$} \\
\hline - Only child & 9 & 9.0 \\
\hline - 1 & 26 & 26.0 \\
\hline - 2 & 44 & 44.0 \\
\hline - $3+$ & 21 & 21.0 \\
\hline
\end{tabular}

Table (3): Hospitalization and Follow-up of Epileptic Children

\begin{tabular}{|c|c|c|}
\hline Hospitalization \& follow-up data & $\begin{array}{c}\text { No } \\
(\mathbf{n = 1 0 0})\end{array}$ & \% \\
\hline Previous hospitalization in last year due to seizures & & \\
\hline - Yes & 80 & 80.0 \\
\hline - No & 20 & 20.0 \\
\hline Number of previous hospitalization in last year & $\mathbf{n = 8 0}$ & \\
\hline - Once & 37 & 46.3 \\
\hline - Twice & 19 & 23.7 \\
\hline - Others & 21 & 26.3 \\
\hline Regular follow-up & 3 & 3.7 \\
\hline - Yes & $\mathbf{n = 1 0 0}$ & \\
\hline - No & 97 & 97.0 \\
\hline Nearness of follow-up place to home & 3 & 3.0 \\
\hline - Yes & $\mathbf{n = 1 0 0}$ & \\
\hline No & 12 & 12.0 \\
\hline
\end{tabular}


Ghada Gamal Mohamed Badawy et. al.

Table (4): Mothers' Safety Precautions for their Children's Epileptic Seizures and Aura
\begin{tabular}{|l|c|c|}
\hline \multicolumn{1}{|c|}{ Safety Precautions } & No=100 & $\%$ \\
\hline Safety Precautions of Epileptic Seizures & & \\
\hline Notify school about child illness & 63 & 63.0 \\
\hline Avoid leaving child in a bathtub full of water & 42 & 42.0 \\
\hline Prevent child from a contact with sharp objects & 39 & 39.0 \\
\hline Avoid child riding of bicycle alone & 36 & 36.0 \\
\hline Avoid leaving child showering alone & 31 & 31.0 \\
\hline Avid leaving child swim alone & 30 & 30.0 \\
\hline Prevent child from closing bath room from inside & 28 & 28.0 \\
\hline Keep a note to record seizures & 15 & 15.0 \\
\hline Carry a medical alarm & 0 & 0.0 \\
\hline Safety Precautions when child feels Aura & & \\
\hline - Stay with child & 60 & 60.0 \\
\hline - Keep things that may cause injury away & 56 & 56.0 \\
\hline - Prevent child from leaving home & 56 & 56.0 \\
\hline - Roll child on his side on ground & 26 & 26.0 \\
\hline
\end{tabular}

\#More than one answer

Table (5): Mothers' Drugs Management

\begin{tabular}{|l|c|c|}
\hline \multicolumn{1}{|c|}{ Management } & $\begin{array}{c}\text { No } \\
(\mathbf{n = 1 0 0})\end{array}$ & \% \\
\hline Drugs Management & & \\
\hline Giving drugs on times & 68 & 68.0 \\
\hline Don't give alternative drugs without doctor consultation & 51 & 51.0 \\
\hline Management when epileptic seizures decreased \# & & \\
\hline - Continue to give treatment & 31 & 31.0 \\
\hline - Consult doctor to reduce dose & 31 & 31.0 \\
\hline - Decrease dose by herself & 26 & 26.0 \\
\hline - Stop drugs & 19 & 19.0 \\
\hline Management for prevention of dose forgetfulness \# & & \\
\hline - Link drug with a daily routine, e.g., with meal & 47 & 47.0 \\
\hline - Set alarm clock $\quad$ Family remind her & 23 & 23.0 \\
\hline - Did nothing & 19 & 19.0 \\
\hline Management when child infected with acute illness & 20 & 20.0 \\
\hline - Use common known medications & & \\
\hline - Consult doctor & 79 & 79.0 \\
\hline Management of drugs side effects \# & 21 & 21.0 \\
\hline - Ask Doctor & & \\
\hline - Continue to give same dose & 33 & 33.0 \\
\hline - Decrease the dose & 9 & 9.0 \\
\hline - Stop drug & 7 & 7.0 \\
\hline - Didn't gave attention to side effects & 1 & 1.0 \\
\hline
\end{tabular}

\# More than one answer 


\begin{tabular}{|c|c|c|}
\hline Management & $\begin{array}{c}\text { No } \\
(n=100)\end{array}$ & $\%$ \\
\hline \multicolumn{3}{|l|}{ Maternal Management } \\
\hline $\begin{array}{l}\text { Stay with child until seizure ends and restore his } \\
\text { consciousness }\end{array}$ & 100 & 100.0 \\
\hline Remove hard objects that cause injury & 84 & 84.0 \\
\hline Loosen tight clothes around neck and chest & 61 & 61.0 \\
\hline Time seizure duration & 36 & 36.0 \\
\hline Place child on his side & 24 & 24.0 \\
\hline Place something soft under head & 18 & 18.0 \\
\hline Keep calm & 4 & 4.0 \\
\hline \multicolumn{3}{|l|}{ Harmful Unnecessary Procedures } \\
\hline - $\quad$ Bribe face with water & 62 & 62.0 \\
\hline - $\quad$ Restrain child & 39 & 39.0 \\
\hline - Put anything solid like a spoon in mouth & 36 & 36.0 \\
\hline - Give any treatment in mouth & 30 & 30.0 \\
\hline
\end{tabular}

\section{\# More than one answer}

Table (7). Maternal Management of their Children after Epileptic Seizures

\begin{tabular}{|l|c|c|}
\hline \multicolumn{1}{|c|}{ Management } & $\begin{array}{c}\text { No } \\
\text { (n=100) }\end{array}$ & \% \\
\hline Maternal Management & & \\
\hline Clean child's mouth & 99 & 99.0 \\
\hline $\begin{array}{l}\text { Observe child's level of consciousness } \\
\text { Observe breathing and general condition }\end{array}$ & 94 & 94.0 \\
\hline $\begin{array}{l}\text { Examine for involuntary urination or defecation } \\
\text { Observe child mobility and ability to move limbs }\end{array}$ & 75 & 75.0 \\
\hline Check child for any wounds or injuries & 54 & 72.0 \\
\hline $\begin{array}{l}\text { Delay introducing food or drink until child fully regain his } \\
\text { consciousness }\end{array}$ & 42 & 42.0 \\
\hline Keep child on his side or on back and head turned to one side & 36 & 36.0 \\
\hline Record after seizures \# & 21 & 21.0 \\
\hline$\quad$ Duration in minutes & 13 & 13.0 \\
\hline$\quad$ Time of seizure (date/ day/ time) & 12 & 12.0 \\
\hline - Child's activities before seizure & 5 & 5.0 \\
\hline$\quad$ Child's general condition & 4 & 4.0 \\
\hline \# More than one answer & & \\
\hline \hline
\end{tabular}




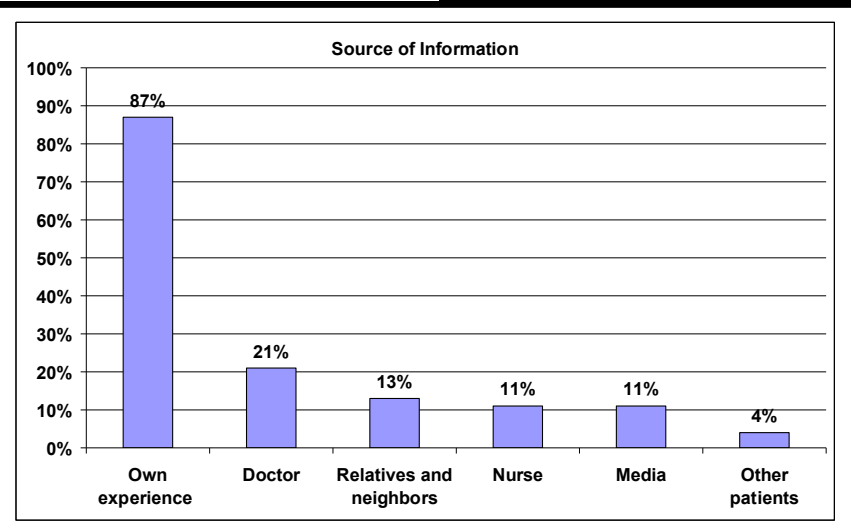

Figure (I): Mothers' Source of Information Regarding Management of Epilepsy

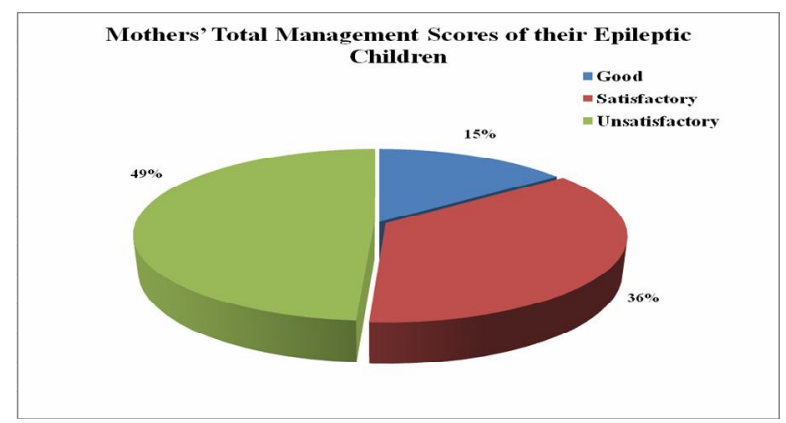

Figure (II): Mothers' Total Management Scores of their Children Epileptic Seizures

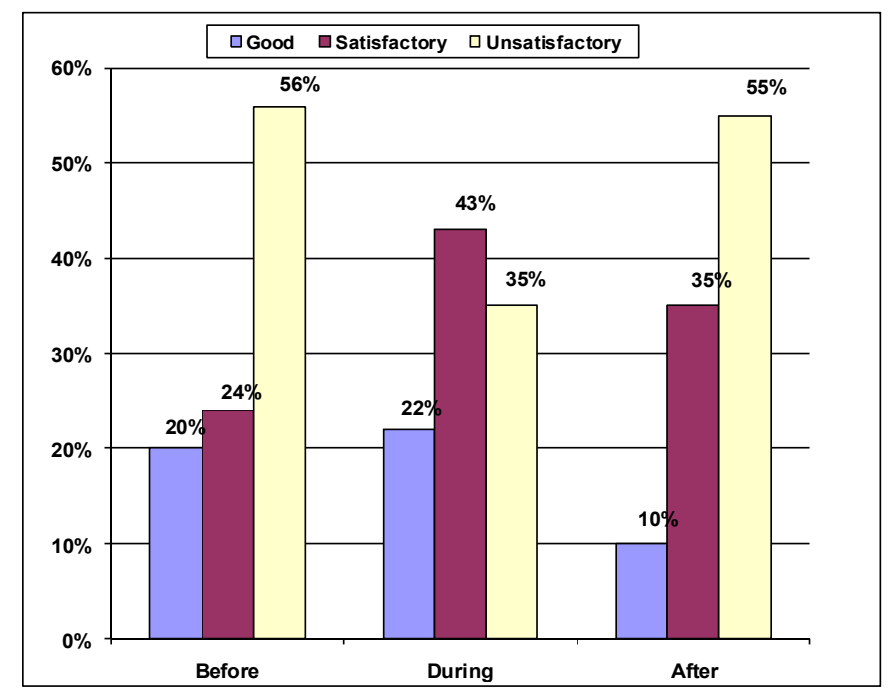

Figure (III): Mothers' Management Scores before, during and after their Children Epileptic Seizures 
Table (8): Total Maternal Management of their Epileptic Children According to their Characteristics

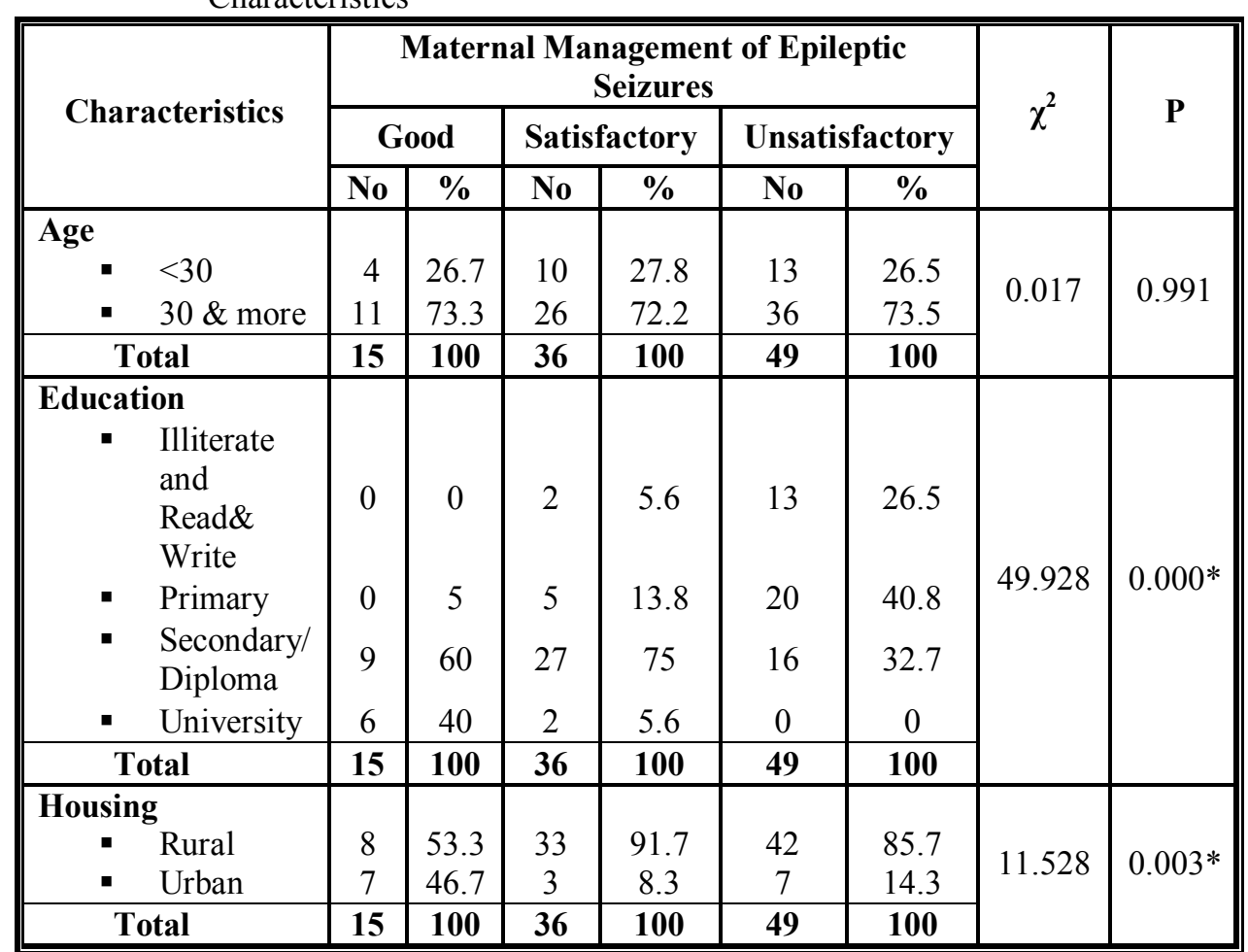

(*) Statistically Significant at $\mathrm{p} \leq 0.05$

\section{Discussion:}

Epilepsy is a common neurological disorder in children and can have a major impact on children's development. Epilepsy starts in childhood in $60 \%$ of cases and most of the clinically significant aspects of the disease occur during childhood $^{(9,10)}$.

The finding of the current study revealed that more than half of the studied children were in the age 6 to less than 12 years, while slightly less than one third of them were in age less than 6 years of age. This finding is supported by Mansy et al., (2012) ${ }^{(11)}$ who reported that epilepsy was more prevalent in children younger than 12 years of age. The finding of the current study may be explained in the fact that it is the age characterized by increase in activities which may increase the risk of exposure to infections and accidents that might affect the integrity of nervous system that may lead to epilepsy.

The present study showed that most of the epileptic children are living in rural areas. This finding may be attributed to the limited access to health services and poor health literacy of families resident in rural areas beside the higher rates of consanguineous marriage and home delivery that may increase the risk of developing epilepsy in rural areas than urban. This finding is congruent with $\boldsymbol{E l}$ Senousey et al., (2009) ${ }^{(12)}$ \& Mahmoud, (2009) ${ }^{(13)}$, who reported that the higher 
incidence of children epilepsy among rural residents.

Mothers' management of their epileptic children play the most significant role in helping their epileptic children adapt to their condition, their function include providing the safety precautions for their children in and outside home, ensuring their children's compliance with treatment, providing care before, during and after the attack $^{(7)}$.

Glauser et al (2012), ${ }^{(14)}$ reported that safety precaution is a priority in epilepsy management. It is clear from the finding of the present study that, about two thirds of mothers stated that they notified the school about their children's illness. This finding can be a result of mothers being particularly concerned about the unpredictable risk that seizures place on their children and they want to ensure their safety until they return home. Moreover, mothers may felt that informing the staff member at the school about their children's epilepsy ensured the safety of the children during all aspects of the day in the event of a seizure. This finding is in agreement with Buelow et al.,(2006) ${ }^{(15)}$ who reported in their study that most parents communicate and interact with school personnel about their children's condition. The minority of mothers mentioned that they prevented their children from closing bath room door from the inside, prevented their children from using computer and watching T.V for long periods (Table IV). These findings may return to mothers' unawareness about the importance of safety precautions, as well as mothers' safety restrictions and limitations may be difficult for the children to apply, where the children need to enjoy the same activities as their peers, and maintain a sense of normalcy.

Regarding safety measures that should be taken by mothers if the children are experiencing an aura before the onset of a seizure, it was found that most of the mothers didn't lie down the children on their side on the ground to prevent their injuries (Table VI). This finding may be returned to the unpredictable nature of their children epileptic seizures. This finding is supported by Dimberg and Burns, (2005) ${ }^{(16)}$ who reported that there is a gap in mothers' knowledge in relation to prediction of aura and taking safety measures accordingly.

It is obvious from the current study that none of the children carried the medical alarm. This finding could be due to mothers' unawareness about benefits of wearing medical alarm and absence of Egyptian culture and medical staff about its importance for epilepsy. Similar observation was mentioned by Taylor et al.,(20110 ${ }^{(17)}$ who found that there is only one child was wearing the medical alarm in their study.

In relation to mothers' management of drugs, it was found that the majority of the studied mothers gave the AEDs on times. This finding could be returned to the instructions from health team member about the importance of adhering to AEDs regimen that create awareness for the mothers or may be due to the fact that the children get their antiepileptic drugs for free and regularly from the health insurance hospitals. This finding is supported by Faught et al.,(2009) ${ }^{(18)}$ who found a high level of drug compliance.

It was found in these study findings that most of the mothers were following methods to remember the medication time as link drug with a daily routine, e.g., with meal or setting the alarm clock to prevent dose forgetfulness. This finding may be explained by the stress of health team on the importance of adhering to medication regimen and may be due to mothers' observations that seizures frequency decreased when their children were taking the drug regularly. This finding is supported by Davidson et al.,(2007) (19) who stated that mothers should setting 
strategies to anti-epileptic medications regimen to prevent missing doses.

Regarding mothers' management when epileptic seizures decreased in frequency, the result of the present study revealed that the minority of the mothers either decreased or stopped the dose without medical consultation. This finding may be attributed to mothers' unawareness about the importance of consulting physician before changing the medication regimen. This finding is consistent with many studies as Hammad,(1992) ${ }^{(20)}$; Bassili et al.,(2002) $)^{(21)}$ and El-Sharkawy et al.,(2006) (22) where they found lack of adherence with medications either by decreasing or stopping the AEDs.

Although Perucca and Kwan, (2005) ${ }^{(23)}$ noted that the interactions with other medications or even other substances can attenuate or potentiate metabolic consumption of anti-epileptic medication that may lead to an excessive drug load, leading to suboptimal outcomes, including greater incidence or severity of sideeffects or even increased the frequency of seizures, the majority of the studied mothers in this study used the known medications without medical consultation when their children infected with an acute illness. This finding may be due to the poor knowledge of mothers about AEDs and medication interactions.

Concerning mothers' management during the epileptic seizure, most of them knew what to do during the epileptic seizure, where all the mothers mentioned that they stayed with their children until seizure ends and restore their consciousness and removed the hard objects that cause injury. This finding may be due to their fears on their children so they can't leave them during the attack and try to protect them. In addition, two thirds of the mothers had either "good" or "satisfactory" scores in their management during the epileptic seizures. This finding may be due to the frequent hospitalization of the majority of the children that leads to the closeness of mothers to the health care members and have the chance to observe what they do. Also, this finding may be the result of the instructions that mothers have from the health team members during the frequent follow - up visits. This finding was supported by the study carried out in Saudi Arabia by Zainy et al.,(2013) ${ }^{(10) .}$

Many mothers in the present study performed unnecessary or even harmful procedures during the epileptic seizures, as bribing face with water, restraining their children and putting anything solid like a spoon in their mouth (Table VI). This finding could be due to mothers' adherence to old beliefs in caring for the epileptic individual that were wrongly recommended, e.g., put a spoon in mouth to prevent tongue biting. These beliefs are exclusively present especially in rural regions. This finding is supported by Frank-Briggs and Alikor,(2011) ${ }^{(24)}$ who found in their study that many harmful procedures in caring of the epileptic children were performed.

The current study findings revealed that the majority of the mothers clean their children's mouth from saliva, observe the children's level of awareness, their breathing, and their general condition as well as examine the children for involuntary urination or defecation after the seizures. It is clear from these cares that mothers provide the care for visible signs and neglected the hidden ones as, keep the children on their side or on back and head turned to one side. This finding is supported by the fact that more than half of the mothers had "unsatisfactory" scores regarding their management after the epileptic seizures. Also, Price and Gwin, (2008) $^{(25)}$ described a similar finding in their study as they reported that many mothers did not perform the care after seizures.

The current study showed that the minority of the mothers record the time, duration 
and signs of epileptic seizures. This finding may be the result of lack of instruction given by the health team members regarding the importance of recording of the epileptic seizures or they may do not ask mothers about the records. Also, mothers may be busy by home activities especially in rural areas or they getting used to the illness of the chronic nature, so they did not record. This finding was supported by Monir et al.,(2013) (26) who found that mothers didn't record the seizure events.

The total management scores of half of the mothers in the present study were either "good" or "satisfactory" scores. This may be returned to the fact that the majority of mothers in the present study were housewives that provide them with more available time and saved effort than working mothers to give better management to their epileptic children. This finding is consistent with Beca et al.,(2008) $)^{(27)}$, which revealed that most of the mothers in their study had "satisfactory" level of epilepsy management regardless of their "poor" level of knowledge.

As regards mothers' management scores according to their education, the current study revealed that there was statistical significant relation between mothers' management and their education. It was found that the majority of the mothers who completed their secondary / diploma education and the university level had "good" and "satisfactory" scores in their management. This finding could be explained in the light of the fact that education might helped in providing better care, where they gain understanding of the importance of regular therapy and management. This finding is supported by Wada et al.,(2001) ${ }^{(28)}$ and Guekht et al., (2007) $^{(29)}$ who found that children of educated mothers had an optimal management compared to the children with illiterate ones.
Regarding mothers' management scores of their epileptic children according to their age, the current study revealed that the majority of mothers aged 30 years \& more had "good" and "satisfactory" scores respectively regarding their management throughout the study. This finding may be explained in the light of the fact that mothers depend on their experience as a source of information (Figure I), where their experience increased with their age or may be due to the chronic nature of the disorder which lasts over time. This finding is supported by Shore et al.,(2009) (30) who found that mothers' care was better in older mothers than younger age ones.

\section{Conclusion:}

Based on the findings of the current study, it is concluded that half of mother's total management practices of their epileptic children were either "good: or "satisfactory". There were statistical significant differences found between mothers' management scores and their characteristics in area related to education and their level of education, where the older the age and the higher education the better management scores the mothers have.

Recommendations:

Based on the findings of the present study, the following recommendations are to be considered:

1. Regular and continuous health educational programs are essential for mothers of epileptic children about care of their children and their community resources.

2. Manual booklet and pamphlets about epilepsy and its management must be available to epileptic children and their parents which up to their understanding and cultural background.

3. Establishing a support group for epileptic children and their mothers is mandatory to support mothers' management. 
Acknowledgements:

We would like to thank all the mothers' who participated in the study and Epileptic clinic staff of the out-patient department of Mansoura University Children Hospital for their help and cooperation during the study period and appreciate the great efforts of our supervisors in this work.

Corresponding author:

Ghada Gamal Mohamed Badawy

Pediatric Nursing Department, Faculty of Nursing, Mansoura University.

\section{References:}

1. Hockenberry, M. and Wilson, D., (2013): Wong`s Essential of Pediatric Nursing., The Child with Cerebral Dysfunction, $9^{\text {th }}$ edition; Mosby, Elsevier, USA, pp 956:966.

2. Kligman, R.; Stanton, B. and Geme, J. et al., (2012): Nelson Textbook of Pediatrics, The Nervous System. Seizure in Childhood. $19^{\text {th }}$ edition., Philadelphia., Elsevier.

3. Babicar, D. and Abbas, IM., (2012): Knoweledge, practice and attitude toward epilepsy among primary and secondary school teachers in south Gezira locality, Gezira state, sudan. Journal of Family and Community Medicine; Vol 18 (1):17-21

4. Kandil, M.; Ahmed, W.; and Sayed, M. et al., (2007): pattern of epilepsy in childhood and adolescence: a hospitalbased study. African Journal of Neurological Sciences; Vol. 26, No 1.

5. Farghaly, W.; Nagiub, $H$. and Rageh, T. et al., (2012): Epidemiology of epilepsy in Egypt. Neuroepidemiology; vol./is. 39/34(253), 0251-5350.

6. Duffy, LV., (2011): Parental coping and childhood epilepsy: the need for future research. Journal Neuroscience Nursing; Vol.43, No.1:pp. 29-35.

7. Rodenburg, R.; Wagner, JL. and Austin, JK. et al., (2011): Psychosocial issues for children with epilepsy. J Epilepsy \& Behavior; 22: 47-54.

8. Royal College of Pediatrics and Child Health (RCPCH), (2012):

United Kingdom collaborative clinical audit of health care for children and young people with suspected epileptic seizures, National Report September 2012, Available online at: www.rcpch.ac.uk/epilepsy12

9. Jan, MM., (2005): Clinical review of pediatric epilepsy. Neurosciences; 10 : 255-264.

10. Zainy, LE.; Atteyah, DM. and Aldisi, WM., (2013): Parents' knowledge and attitudes toward children with epilepsy. Neurosciences J; Vol. 18 (4).

11. Mansy, G.; Elshehawy, A. and Elsayed, E. et al., (2012): Maternal practice and its effect on Quality of Life of their Epileptic Children, Nature and Science; $10(2)$.

12. El-Senousey, MY.; El-Beshlawy, WF. and El-Seidy, E. et al., (2009): Infantile and Childhood Epilepsies in Middle Delta: Types, Risk Factors and Etiology, Departments of Neuropsychiatry, Radiology, Tanta University. Egypt J. Neurol. Psychiat. Neurosurg; 46(1): 151-160.

13. Mahmoud, NA., (2009): Prevalence of Epilepsy in Primary School Children in El-Minia City, Egypt. Department of Neurology and Psychiatry, El-Minia University. Egypt J. Neurol. Psychiat. Neurosurg; 46(1):33-39.

14. Buelow, JM.; McNelis, A.; Shore, CP. and Austin, JK., (2006): Stressors of parents of children with epilepsy and intellectual disability. Journal of Neuroscience Nursing 38(3):147-154.

15. Glauser, T.; Cross, H. and Duchtowny, M. et al., (2012): Pediatric Epilepsy. Seizures in 
Childhood, McGroaw Hill Professional com., pp 450-455.

16. Dimberg, EL. and Burns, TM., (2005): Management of common neurologic conditions in sports. Clinics in Sports Medicine 24(3):637-662.

17. Taylor, J.; Jacoby,A.; Baker,GA. and Marson,AG.,(2011): Selfreported and parent-reported quality of life of children and adolescents with new-onset epilepsy. Epilepsia 52(8):1489-1498.

18. Faught, RE.; Weiner,JR. and Guerin,A. et al.,(2009): Impact of nonadherence to antiepileptic drugs on health care utilization and costs: Findings from the RANSOM study. Epilepsia 50(3):501-509.

19. Davidson, M.; Dorris, L.; O’Regan, M. and Zuberi, SM., (2007): Memory consolidation and accelerated forgetting in children with idiopathic generalized epilepsy. Epilepsy \& Behavior; 11., 394-400.

20. Hammad, HA., (1992): Statistical studies on epileptic patients attending the epilepsy clinics of Alexandria University Hospitals in the past ten years. Msc. Thesis in Neuropsychiatry, Faculty of Medicine, Alexandria University.

21. Bassili, A.; Omar, T. and Zaki, A. et al., (2002): Pattern of diagnostic and therapeutic care of childhood epilepsy in Alexandria, Egypt. Int J Qual Health Care (2002) 14 (4): 277-284. doi: 10.1093/intqhe/14.4.277.

22. El-Sharkawy, G.; Newton, C. and Hartley, S., (2006): Attitudes and practices of families and health care personnel toward children with epilepsy in Kilifi, Kenya. Epilepsy Behav; 8:201-12.

23. Perucca, E. and Kwan, P., (2005): Overtreatment in epilepsy: How it occurs and how it can be avoided. CNS Drugs 19(11):897-908.
24. Frank-Briggs, A. and Alikor, E., (2011): Knowledge and attitudes of parents toward children with epilepsy; Annals of African Medicine Vol. 10, No. 3; 238-242.

25. Price, D. and Gwin, J. (2008): Pediatric Nursing An Introductory Text, $10^{\text {th }}$ edition. Saunders Elsevier. Seizures disorder; pp 252-256.

26. Monir, ZM.; EL-Alameey, IR. And Eltahlawy, E. (2013): Health related quality of life of children with epilepsy in Egypt. Journal of The Arab Society for Medical Research (8:53-66).

27. Baca, CB.; Vickrey, BG. and Hays, RD., (2010): Differences in child versus parent reports of the child's health-related quality of life in children with epilepsy and healthy siblings. Value in health; Volume 13, Issue 6, Pages 778-786.

28. Wada, K.; Kawata, Y. and Murakami, T. et al., (2001):Sociomedical aspects of epileptic patients: their employment and marital status. Psychiatry Clin Neurosci; 55:141-146.

29. Guekht, AB.; Mitrokhina, TV. and Lebedeva, AV. et al., (2007):Factors influencing on quality of life in people with epilepsy. Seizure; 16:128-133.

30. Shore, CP.; Buelow, JM.; Austin, JK. and Johnson, CS., (2009): Continuing psychosocial care needs in children with new-onset epilepsy and their parents. Journal of Neuroscience Nursing 41(5):244-250. 